\title{
Energy expenditure in congenital heart disease
}

\author{
J S Barton, P C Hindmarsh, C M Scrimgeour, M J Rennie, M A Preece
}

\begin{abstract}
Growth failure is a well recognised consequence of severe congenital heart disease. Total daily energy expenditure (TDEE) was investigated in eight infants with severe congenital heart disease to determine whether an increase in this parameter is an important factor in their failure to thrive, and to estimate the energy intake that would be required to allow normal growth. The infants were studied over a seven day period before surgery using the doubly labelled water method. Growth failure was evident; their mean age standardised body mass index was $\mathbf{8 0} \%$ of the expected value. Mean TDEE was 425 $\mathrm{kJ} / \mathrm{kg}$, significantly greater than in healthy infants (mean TDEE/kg SD score $=+1 \cdot 4$; $95 \%$ confidence interval $+0 \cdot 27$ to $+2 \cdot 57$ ). In contrast, their energy intake was only $82 \%$ of the estimated average requirements. It was estimated that in early infancy a gross energy intake of 600 $\mathrm{kJ} / \mathrm{kg} / \mathrm{day}$ is required for normal growth in patients with congenital heart disease. This is unlikely to be achieved by energy supplements alone and early recourse to nasogastric feeding should be considered.

(Arch Dis Child 1994; 70: 5-9)
\end{abstract}

Growth failure is a recognised consequence of severe congenital heart disease, particularly when associated with a large left to right shunt and pulmonary hypertension. ${ }^{1}$ The characteristic reductions in energy intake and increases in resting energy expenditure ${ }^{2}$ seen in these infants may be responsible for their failure to thrive. Data on total daily energy expenditure (TDEE) in congenital heart disease would be of value in understanding the growth failure of these infants and in planning adequate nutritional support. The measurement of TDEE is difficult, however. Traditional methods of direct or indirect calorimetry require the isolation of the subject for prolonged periods, which would be inappropriate for these infants, and extrapolation from shorter periods of respiratory gas exchange is associated with significant errors, ${ }^{3}$ especially as activity cannot be standardised. TDEE can now be measured non-invasively in free living infants using the doubly labelled water method; normal values for energy expenditure have been reported for healthy breast and bottle fed infants during the first year of life. ${ }^{4}$ The aim of this study was to obtain comparable information for a small group of infants with severe congenital heart disease, in some both before and after corrective cardiac surgery.

\section{Patients and methods}

Eight infants (four boys, four girls), all with severe congenital heart disease, aged $0.23-0.58$ years, and weighing $3.57-6.53 \mathrm{~kg}$ were studied. In each infant corrective cardiac surgery had become the preferred treatment within the first six months of life because of poor symptom control and failure to thrive, despite the best possible medical management. Patients were identified from the surgical waiting list and were studied at home over a five to seven day period before admission to hospital. The studies were repeated in four of the infants after surgical intervention.

Energy supplements to a normal diet taken by mouth were used in four patients and nasogastric feeding in one (patient 2); in these patients the energy density was between 300 and $350 \mathrm{~kJ} / 100 \mathrm{ml}$, the carbohydrate content was $8-12 \%$, and the fat content was $3 \cdot 6-3 \cdot 8 \%$. All those with a left to right shunt were treated with frusemide $(1 \mathrm{mg} / \mathrm{kg} /$ day) and spironolactone $(3 \mathrm{mg} / \mathrm{kg} / \mathrm{day})$, with the addition of digoxin $(0.01 \mathrm{mg} / \mathrm{kg} /$ day $)$ or captopril (1-3 mg/kg/day) for those in heart failure. All the patients were free from intercurrent infection or other illness at the time of study.

TDEE was determined using the doubly labelled water technique and compared with data from healthy infants of the same age. ${ }^{4}$ This technique for estimating energy expenditure has previously been validated in infants in hospital after surgery. ${ }^{5}$ Briefly, water containing two stable, non-radioactive isotopes of oxygen and hydrogen $\left(\mathrm{H}_{2}{ }^{18} \mathrm{O}\right.$ and $\left.{ }^{2} \mathrm{H}_{2} \mathrm{O}\right)$ were administered, taking care to avoid any spillage, via a syringe, feeding bottle, or nasogastric tube according to the child's usual method of feeding. The labelled water was weighed to the nearest $0.01 \mathrm{~g}$ and given in doses of $0.3 \mathrm{~g}$ $\mathrm{H}_{2}{ }^{18} \mathrm{O}$ and $0.25 \mathrm{~g}^{2} \mathrm{H}_{2} \mathrm{O}$ for each $\mathrm{kg}$ of estimated total body water. Water labelled with ${ }^{18} \mathrm{O}$ (Isotec, Miamisburg, USA) and with ${ }^{2} \mathrm{H}$ (Sigma, Poole) were 9.8 and 99.8 atom \% respectively.

Urine was extracted from cotton wool balls placed in disposable napkins. ${ }^{6}$ Samples were 
collected before administration of the labelled water, about five hours later (for total body water estimation), and then daily for five to seven days to determine the relative rates of loss of ${ }^{2} \mathrm{H}$ and ${ }^{18} \mathrm{O}$ from the body water pool. The collection time of each sample was recorded.

Isotopic enrichment of the urine samples was measured relative to a local standard by isotope ratio mass spectrometry (Finnigan MAT Model Delta D) using previously described methods. ${ }^{7}$ A rate constant for the disappearance of each isotope was then determined. The difference in the elimination rates of the two isotopes is proportional to the total carbon dioxide production as, through the action of carbonic anhydrase, ${ }^{18} \mathrm{O}$ elimination is the result of both carbon dioxide production and loss of water from the body, whereas ${ }^{2} \mathrm{H}$ is lost only as water. The mean TDEE over the study period can then be calculated using Weir's equation ${ }^{8}$ assuming a predicted respiratory quotient of 0.85 reported for healthy infants of this age. ${ }^{9}$ Some of the infants studied, however, were receiving carbohydrate supplements which might be expected to increase their food quotient. In healthy subjects who maintain energy balance the food quotient is equivalent to the respiratory quotient over the relatively long period of a double isotope study. ${ }^{9}$ Dietary data were available from seven of the infants studied from which food quotients could be derived for each individual patient. The mean (SE) food quotient allowing for the growth observed over the study period of the infants studied was $0.87(0.005)$. Using the individual food quotient values to determine energy expenditure for each subject would have reduced the TDEE by a maximum of $3.6 \%$ in one patient with a mean reduction of less than $2 \%$.

Body weight was measured to the nearest 10 $g$ at the beginning and end of the study period; supine length was recorded at the outset. The age standardised body mass index (BMI), equal to weight/height ${ }^{2}$ (\%BMI), which relates weight and height to the expected (50th centile) value for age, was calculated according to the method of Cole. ${ }^{10}$

Total body water (TBW) was estimated from the $\mathrm{H}_{2}{ }^{18} \mathrm{O}$ dilution in basal urine samples and urine samples taken five hours after the dose of radiolabelled water. ${ }^{11}$ Fat free mass (FFM) was calculated, assuming the water content of the FFM at this age to be $80 \%$ by weight, ${ }^{12}$ as $\mathrm{FFM}=\mathrm{TBW} / 0 \cdot 8$; body fat =total body weight -FFM.
As far as we are aware the doubly labelled water technique has not previously been used to determine the TDEE in subjects with congenital heart disease and it is therefore important to consider how abnormalities in fluid metabolism might influence the data on energy expenditure obtained using this method. An increase in interstitial water (oedema) due to cardiac failure would prolong the time necessary for isotope equilibration to occur throughout the body water pool. Failure to allow for this would result in an underestimate of the TBW and consequently in the estimated TDEE. All of the infants in this study were receiving long term treatment with diuretics and none was clinically oedematous or in poorly controlled cardiac failure when studied. The TBW value was therefore calculated from the ${ }^{18} \mathrm{O}$ dilution in urine obtained at the usual time after isotope administration. ${ }^{11}$ Treatment with diuretics, tachypnoea, and excessive sweating might all be expected to increase the water turnover rate in patients with congenital heart disease. Providing that the difference between the rate constants for ${ }^{18} \mathrm{O}$ and ${ }^{2} \mathrm{H}$ is sufficiently large to be accurately determined, however, a rapid turnover of body water will not influence the calculation of TDEE and had the advantage of shortening the necessary study period which depends on the isotopes' biological half lives.

The infants studied were all receiving a mixed diet. During the study period a three day dietary record was kept using household measures to estimate the amount consumed. These records were analysed using computerised food composition tables (Diet 2000, B\&W Electronic Systems, Portsmouth).

The study was approved by the ethics committee of the Hospital for Sick Children, Great Ormond Street, and written parental consent was obtained in all instances.

\section{STATISTICAL ANALYSIS}

The mean and $95 \%$ confidence interval (CI) were calculated for normally distributed data using the Student's $t$ distribution, otherwise the median and range are reported. TDEE data were compared with reference standards using graphical methods and by calculating SD scores by interpolation from log transformed data using the geometric mean and log SD values published by Davies et al. ${ }^{4}$

Table 1 Diagnosis, growth, and energy expenditure before the operation of infants studied

\begin{tabular}{|c|c|c|c|c|c|c|c|c|c|c|c|}
\hline $\begin{array}{l}\text { Patient } \\
\text { No }\end{array}$ & Diagnosis & $\begin{array}{l}\text { Age } \\
\text { (years) }\end{array}$ & Sex & $\begin{array}{l}\text { Length } \\
(\mathrm{cm})\end{array}$ & $\begin{array}{l}\text { Weight } \\
(\mathrm{kg})\end{array}$ & $\begin{array}{l}\% B M I \\
(\%)\end{array}$ & $\begin{array}{l}T D E E \\
(M \mathcal{Y})\end{array}$ & $\begin{array}{l}\text { TDEE } \\
(M \mathcal{M f k g})\end{array}$ & $\begin{array}{l}T D E E \\
\left(M^{\prime} / k^{0.5}\right)\end{array}$ & $\begin{array}{l}T B W \\
(\mathrm{~kg})\end{array}$ & $\begin{array}{l}F F M \\
(\mathrm{~kg})\end{array}$ \\
\hline $\begin{array}{l}1 \\
2 \\
3 \\
4\end{array}$ & $\begin{array}{l}\text { TGA, previous BAS } \\
\text { VSD, PHT, CCF } \\
\text { VSD, PHD, CCF } \\
\text { AVSD, PHT, CCF, }\end{array}$ & $\begin{array}{l}0.32 \\
0.53 \\
0.31\end{array}$ & $\begin{array}{l}\mathbf{M} \\
\mathbf{M} \\
\mathbf{M}\end{array}$ & $\begin{array}{l}59 \cdot 8 \\
59 \cdot 9 \\
62 \cdot 8\end{array}$ & $\begin{array}{l}4 \cdot 68 \\
4 \cdot 69 \\
5 \cdot 23\end{array}$ & $\begin{array}{l}78 \cdot 7 \\
76 \cdot 6 \\
80 \cdot 4\end{array}$ & $\begin{array}{l}1 \cdot 53 \\
3 \cdot 13 \\
2 \cdot 17\end{array}$ & $\begin{array}{l}0.33 \\
0.66 \\
0.41\end{array}$ & $\begin{array}{l}0.7 \\
1.44 \\
0.95\end{array}$ & $\begin{array}{l}3.69 \\
3.29 \\
3.75\end{array}$ & $\begin{array}{l}4 \cdot 61 \\
4 \cdot 11 \\
4 \cdot 68\end{array}$ \\
\hline 5 & $\begin{array}{l}\text { Down's syndrome } \\
\text { AVSD, PHT, CCF, }\end{array}$ & 0.23 & $\mathrm{~F}$ & $53 \cdot 8$ & 3.57 & $75 \cdot 7$ & 1.5 & 0.42 & 0.8 & $2 \cdot 75$ & $3 \cdot 44$ \\
\hline $\begin{array}{l}6 \\
7 \\
8\end{array}$ & $\begin{array}{l}\text { Down's syndrome } \\
\text { VSD, PHT } \\
\text { VSD } \\
\text { ToF }\end{array}$ & $\begin{array}{l}0.32 \\
0.58 \\
0.39 \\
0.47\end{array}$ & $\begin{array}{l}\mathbf{M} \\
\mathbf{F} \\
\mathbf{F} \\
\mathbf{F}\end{array}$ & $\begin{array}{l}55 \cdot 9 \\
67 \cdot 3 \\
58 \cdot 4 \\
61 \cdot 5\end{array}$ & $\begin{array}{l}4 \cdot 49 \\
6 \cdot 53 \\
4 \cdot 39 \\
5 \cdot 37\end{array}$ & $\begin{array}{l}88 \cdot 4 \\
82 \cdot 9 \\
76 \cdot 2 \\
82 \cdot 5\end{array}$ & $\begin{array}{l}1 \cdot 63 \\
2 \cdot 17 \\
1.97 \\
2 \cdot 43\end{array}$ & $\begin{array}{l}0.36 \\
0.33 \\
0.44 \\
0.44\end{array}$ & $\begin{array}{l}0.77 \\
0.85 \\
0.93 \\
1.04\end{array}$ & $\begin{array}{l}3 \cdot 16 \\
4 \cdot 43 \\
3 \cdot 07 \\
3 \cdot 54\end{array}$ & $\begin{array}{l}3 \cdot 95 \\
5 \cdot 54 \\
3 \cdot 84 \\
4 \cdot 43\end{array}$ \\
\hline \multicolumn{2}{|c|}{ Mean (SE) } & $0.39(0.04)$ & & $59.9(1.5)$ & $4.87(0.31)$ & $80 \cdot 2(1 \cdot 5)$ & $2 \cdot 07(0 \cdot 19)$ & $0.43(0.04)$ & $0.93(0.08)$ & $3.46(0 \cdot 18)$ & $4.33(0.23)$ \\
\hline
\end{tabular}

TGA=transposition of great arteries; $B A S=$ balloon atrial septostomy; $\mathrm{VSD}=$ ventricular septal defect; $\mathrm{PHT}=$ pulmonary hypertension; $\mathrm{CCF}=$ congestive cardiac failure; AVSD=atrioventricular septal defect; $\mathrm{ToF}=$ tetralogy of Fallot; $\mathrm{BMI}=$ body mass index; $\mathrm{TBW}=$ total body water; and FFM=free fat mass 
Table 2 Weight gain, energy intake and total daily energy expenditure (TDEE) before and after cardiac surgery

\begin{tabular}{|c|c|c|c|c|c|c|c|c|c|c|}
\hline \multirow[b]{2}{*}{$\begin{array}{l}\text { Patient } \\
\text { No }\end{array}$} & \multirow[b]{2}{*}{$\begin{array}{l}\text { Birth } \\
\text { weight } \\
\text { (g) }\end{array}$} & \multirow[b]{2}{*}{$\begin{array}{l}\text { Age } \\
\text { (years) }\end{array}$} & \multicolumn{2}{|c|}{ Before study } & \multicolumn{2}{|c|}{$\begin{array}{l}T D E E \\
(\mathrm{kf} / \mathrm{kg} / \text { day })\end{array}$} & \multicolumn{2}{|c|}{$\begin{array}{l}\text { Energy intake } \\
(\mathrm{kf} / \mathrm{kg} / \text { day })\end{array}$} & \multicolumn{2}{|c|}{$\begin{array}{l}\text { Weight gain during } \\
\text { study }(\mathrm{g} / \mathrm{kg} / \text { day })\end{array}$} \\
\hline & & & $\begin{array}{l}\text { Weight } \\
(\mathrm{kg})\end{array}$ & $\begin{array}{l}\text { Weight } \\
\text { gain } \\
\text { (g/day) }\end{array}$ & $\begin{array}{l}\text { Before } \\
\text { surgery }\end{array}$ & $\begin{array}{l}\text { After } \\
\text { surgery }\end{array}$ & $\begin{array}{l}\text { Before } \\
\text { surgery }\end{array}$ & $\begin{array}{l}\text { After } \\
\text { surgery }\end{array}$ & $\begin{array}{l}\text { Before } \\
\text { surgery }\end{array}$ & $\begin{array}{l}\text { After } \\
\text { surgery }\end{array}$ \\
\hline $\begin{array}{l}1 \\
2^{\star} \\
3 \\
4^{\star} \\
5 \\
6 \\
7^{\star} \\
8^{\star}\end{array}$ & $\begin{array}{l}2760 \\
2500 \\
3350 \\
2930 \\
2200 \\
3040 \\
2610 \\
2670\end{array}$ & $\begin{array}{l}0.32 \\
0.53 \\
0.31 \\
0.23 \\
0.32 \\
0.58 \\
0.39 \\
0.47\end{array}$ & $\begin{array}{l}\mathbf{4} \cdot 68 \\
4 \cdot 69 \\
5 \cdot 23 \\
3 \cdot 57 \\
4 \cdot 49 \\
6 \cdot 53 \\
4 \cdot 39 \\
5 \cdot 37\end{array}$ & $\begin{array}{r}16 \cdot 3 \\
11 \cdot 3 \\
16.5 \\
7 \cdot 6 \\
19 \cdot 4 \\
16 \cdot 6 \\
12.5 \\
15.9\end{array}$ & $\begin{array}{l}329 \\
662 \\
412 \\
422 \\
360 \\
331 \\
440 \\
444\end{array}$ & $\begin{array}{r}-\overline{7} \\
315 \\
582 \\
- \\
\overline{-} \\
430 \\
-\end{array}$ & $\begin{array}{c}499 \\
730 \\
434 \\
491 \\
- \\
220 \dagger \\
464 \\
539\end{array}$ & $\begin{array}{r}- \\
363 \\
421 \\
- \\
- \\
- \\
419 \\
-\end{array}$ & $\begin{array}{r}5 \cdot 1 \\
2 \cdot 5 \\
3 \cdot 2 \\
-0 \cdot 5 \\
2 \cdot 2 \\
1 \cdot 9 \\
7 \cdot 1 \\
6\end{array}$ & $\begin{array}{l}- \\
0 \cdot 9 \\
9 \cdot 6 \\
6 \\
- \\
\overline{6} \\
-\end{array}$ \\
\hline \multicolumn{3}{|c|}{ Mean (SE) } & & \multicolumn{3}{|l|}{$14 \cdot 5(1 \cdot 3)$} & \multicolumn{2}{|c|}{$483(57)$} & \multicolumn{2}{|c|}{$3.4(0.9)$} \\
\hline
\end{tabular}

*Infants receiving energy supplements. †This very low energy intake is unexplained. Clearly, if sustained at this rate, weight loss would result.

\section{Results}

Table 1 gives the diagnostic and anthropometric features of the eight infants. All infants showed significant preoperative growth failure with a mean daily weight gain of $14.5(95 \% \mathrm{CI}$ 11.4 to $17 \cdot 7) \mathrm{g}$, considerably less than the 50th centile rates of 31 and $26 \mathrm{~g} /$ day in boys and girls respectively over the initial three months

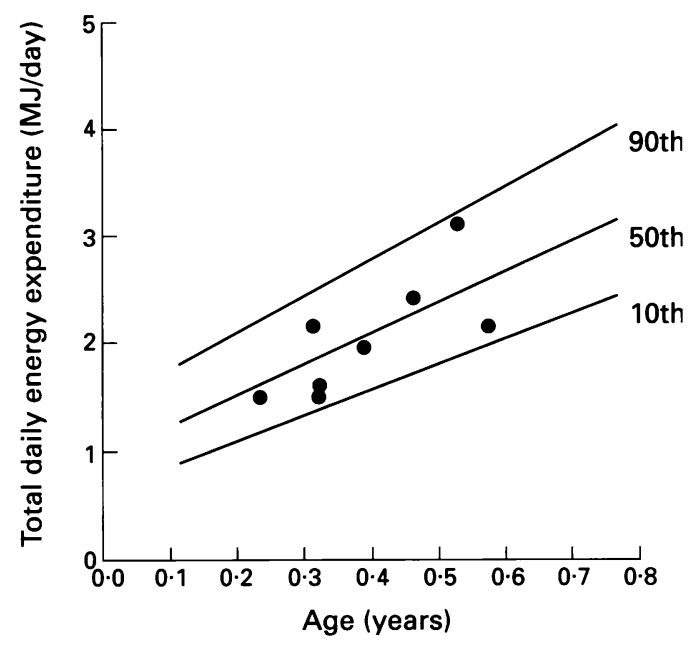

Figure 1 Energy expenditure in infants with congenital heart disease. Total daily energy expenditure (TDEE) determined before the operation by the doubly labelled water method and plotted against age in eight infants with serious congenital heart disease (for details, see text). Centiles are derived from data obtained in normal infants by Davies et al. ${ }^{4}$

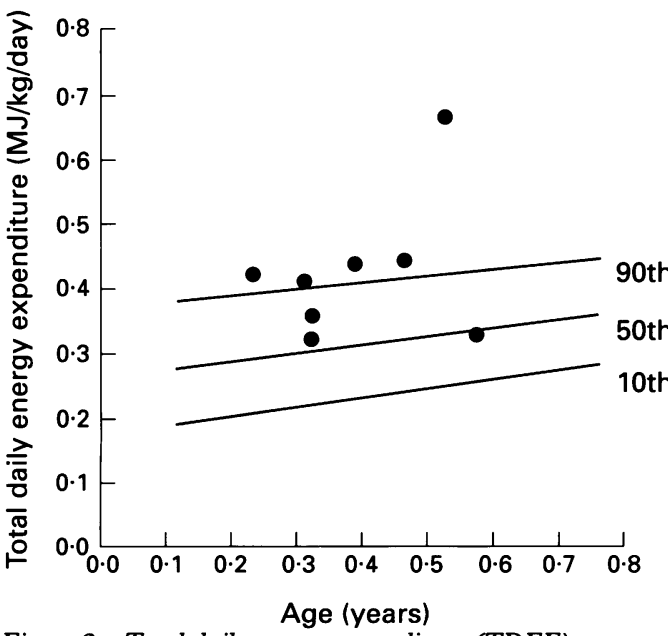

Figure 2 Total daily energy expenditure (TDEE) adjusted for body size in infants with congenital heart disease. TDEE before the operation adjusted for body weight in the same eight infants illustrated in figure 1 . Centiles are derived from data obtained in normal infants by Davies et al. ${ }^{4}$ of life ${ }^{13}$ (table 2). As a result, at the time of study, the median weight centile was on the first and the median length centile the sixth of the Tanner et al standards. ${ }^{14}$ Weight was more severely affected than length, resulting in a markedly reduced mean BMI of $80 \cdot 2 \%(95 \%$ CI $76 \cdot 7$ to $83 \cdot 7)$. Before surgery total body fat (body weight-FFM) (table 1) was significantly reduced; when expressed as a percentage of body weight, the mean percentage of body fat was $10 \cdot 5 \%$ (95\% CI 6 to $15 \%)$ compared with a value of $25 \%$ in reference children of the same age. ${ }^{12}$

The TDEE data from our eight patients with congenital heart disease were similar to those obtained from healthy infants ${ }^{4}$ when expressed as $\mathrm{MJ} /$ day (fig 1). The mean (95\% CI) $\mathrm{SD}$ score for TDEE (MJ/day) was -0.27 $(-1.03$ to +0.49$)$. Total energy expenditure is dependent on body size, however, and in particular the metabolically active tissue mass, and when expressed on a weight basis (fig 2 ) in the infants with congenital heart disease it appeared to be significantly increased (mean TDEE $/ \mathrm{kg}$ SD score $+1 \cdot 40,95 \% \mathrm{CI}+0 \cdot 27$ to $+2 \cdot 57)$.

Expressing energy expenditure in early infancy on the basis of the square root of body weight limits the influence of body weight on energy expenditure. ${ }^{15}$ When expressed in this way these data suggest that infants with congenital heart disease tend to have an increased energy expenditure, but with the small number studied the difference did not reach statistical significance: mean TDEE $\mathrm{MJ} / \mathrm{kg}^{0 \cdot 5} \mathrm{SD}$ score $=+0.60(95 \%$ CI -0.36 to +1.57$)$.

Gross energy intakes, estimated from prospective dietary records (seven infants) taken during the study were variable (table 2). The highest value was observed in an infant (patient 2) who was fed an enriched milk formula via a nasogastric tube. Intake appeared to be reasonable when expressed relative to body weight (mean 483 (95\% CI 344 to 622 ) $\mathrm{kJ} / \mathrm{kg} /$ day), but was less than that recommended for age, ${ }^{16}$ the mean being only $82 \%$ of the estimated average requirement (95\% CI 64 to $101 \%$ ).

No relation was observed between either energy intake or 'spare' energy defined as (energy intake-TDEE) and weight gain during the preoperative study period (Pearson correlation coefficients $r=0.01$ and 0.11 respectively). 
In four patients it was possible to repeat the study postoperatively with a median surgery to restudy interval of 63 days (range 51 to 91 ). No significant changes in median $\% \mathrm{BMI}(76 \%$ before $v 76 \%$ after the operation), sum of triceps and subscapular skinfold thickness $(23 \cdot 2$ $v 26.7 \mathrm{~mm})$, nor percentage body fat $(11.4 v 11.0 \%)$ occurred over this period. No consistent pattern of change in energy expenditure was observed in this small group (table 2).

\section{Discussion}

TDEE is the sum of the energy used to maintain essential metabolic processes and to preserve a constant body mass (maintenance energy requirements) and the energy expended in muscular activity plus that required to synthesise new tissue as a result of growth.

An increase in resting oxygen consumption in congenital heart disease has previously been reported by a number of workers, ${ }^{17} 18$ particularly in patients with pulmonary hypertension and cardiac failure. This hypermetabolism has been related to an increased oxygen consumption by the hypertrophied heart and a stimulation of metabolism due to increased catecholamine secretion. ${ }^{19}$ TDEE has not previously been measured in congenital heart disease. Although maintenance energy requirements are likely to be increased, reflecting the increase in resting oxygen consumption, the energy expended in activity is typically reduced in sick and malnourished children, ${ }^{20}$ and when growth is slow less energy is required for the synthesis of new tissue.

Under these circumstances the TDEE cannot simply be predicted from changes in resting metabolic rate. The TDEE is, however, important in calculating energy requirements for normal growth and activity. Metabolisable energy intake (energy absorbed and available for metabolic purposes) must be sufficient to meet the TDEE and energy stored in new tissue, calculated from the tissue composition and its rate of accretion.

Healthy infants investigated using the methods of this study had an estimated mean (SD) TDEE of $280(60) \mathrm{kJ} / \mathrm{kg} /$ day at 3 months of age. ${ }^{4}$ These subjects were all growing normally and, presumably, had normal levels of activity, in marked contrast with our patients with congenital heart disease, none of whom were thriving.

When the TDEE in infants with congenital heart disease was estimated from respiratory gas exchange during the intervals between feeds it was found to be increased ${ }^{21}$ (mean (SD) TDEE 341 (12) $\mathrm{kJ} / \mathrm{kg} /$ day), though not to the extent observed in our slightly older patients (mean (SE) 425 (38) kJ/kg/day). Although extending the period of respiratory gas exchange to include a complete feed cycle reduces the error in estimating 24 hour energy expenditure, ${ }^{3}$ this approach can only provide a rough estimate of the TDEE as individual activity varies considerably over a 24 hour period. Furthermore, the activity level was scored on a crude four point scale and then related to oxygen consumption, which inevitably introduces additional errors. Finally, in the paper by Jackson and Poskitt energy expenditure was not measured during feeding, a physically demanding activity for infants with cardiorespiratory problems, so that the 24 hour energy expenditure reported was likely to have been an underestimate. ${ }^{21}$ In contrast, our data represent the first attempt to actually measure carbon dioxide production and thence energy expenditure in free living infants with congenital heart disease, and to calculate energy requirements on the basis of measured daily energy expenditure.

Weight gain was less than that expected for age in five of the eight infants during the preoperative study period (table 2) and was significantly slower than normal from birth, even in those infants receiving dietary supplements. Our inability to detect any relation between energy intake and weight gain in these infants is not surprising given the small number of infants studied and the imprecise method used to estimate energy intake. Furthermore such a relation can usually only be shown during periods of rapid growth, ${ }^{20-21}$ whereas before surgery our infants were growing slowly.

Four patients were studied after surgery. Of the other four two died perioperatively, one could not be included because the protocol postoperatively was not complied with, and one infant was lost to follow up. It is difficult to draw firm conclusions from such a small data set, but a few points are of interest. The lack of change in body composition postoperatively is not surprising as the interval between studies inevitably included a period of starvation and catabolism after surgery, followed by the slow resumption of growth and consequently little net difference in size or body fat when restudied. Patient 3 showed a threefold increase in the rate of weight gain when studied after closure of his ventricular septal defect. Gross energy intake was unchanged, but the TDEE had decreased, presumably allowing more energy to be stored in new tissue. Catch up growth has continued in this child with length and weight now lying above the 50th centile at 18 months of age. In contrast, little change in energy intake, expenditure, or weight gain was observed in patient 7 . This girl's ventricular septal defect was of moderate size but no postoperative acceleration in length or weight velocity has occurred, suggesting that the cardiac anomaly was not a major influence on energy metabolism or growth. Finally, the dramatic decrease in energy intake observed in patient 2 resulted from removal of the nasogastric tube after surgery, and may in part have been responsible for his continued slow weight gain despite a reduction in energy expenditure.

Although our study population was small and heterogeneous, including two infants with trisomy 21 , they are generally representative of patients with congenital heart disease presenting in early life. Using data from this and other $^{21}$ studies and a factorial approach to energy utilisation it is possible to estimate the energy requirements of an infant with 
congenital heart disease which must be met if normal growth is to be sustained.

Payne and Waterlow have calculated that the energy cost of normal tissue deposition (Ecg) is $21 \mathrm{~kJ} / \mathrm{g}, 2230 \%$ less than the $31 \mathrm{~kJ} / \mathrm{g}$ estimated in infants with congenital heart disease receiving high energy feeds. ${ }^{21} \mathrm{~A}$ greater energy cost of growth probably reflects the greater fat content of new tissue in the infants with congenital heart disease. This is supported by the significant increase in skinfold thicknesses observed during high energy feeding. ${ }^{21}$ Using this higher value for the energy utilised in growth and assuming that $75 \%$ of the energy cost of growth is stored in new tissue, ${ }^{20}$ whereas the remainder is expended in synthesis (and thus included in the TDEE), the current metabolisable energy intake in these subjects is about $2.4 \mathrm{MJ} /$ day (TDEE plus observed weight gain multiplied by $0.75 \mathrm{Ecg}$ ). From the deficit in weight gain observed during this study, an additional 100 $\mathrm{kJ} /$ day of metabolisable energy would be required to allow normal growth during this period. Careful balance studies have shown that $85 \%$ of the gross energy intake is available for metabolic purposes in infants with congenital heart disease. ${ }^{21}$ Consequently, the goal should be to achieve an energy intake of about $2.9 \mathrm{MJ} /$ day $(600 \mathrm{~kJ} / \mathrm{kg} /$ day $)$ to allow an average rate of weight gain during the first three months of life. Of the infants we have studied only the one fed nasogastrically achieved such a high energy intake. Energy supplements in three other infants fed by mouth did not increase the energy intake much above that observed in infants fed a regular milk formula because of the small volumes ingested. The use of high energy feeds and nasogastric feeding regimens is well tolerated in congenital heart disease and result in catch up growth. ${ }^{23}$

Ronholt Hansen and Dorup, studying an older group of children with congenital heart disease, have also documented a significant reduction in energy intake. ${ }^{24}$ Protein intake was adequate, but the intake of a number of micronutrients was less than the recommended daily allowance. We cannot accurately assess the usual mineral and vitamin intake of the infants in this study because of the brief period for which dietary intake data were collected. Unlike the patients studied by Ronholt Hansen and Dorup, ${ }^{24}$ however, infants in this study received feeds based on a standard infant formula enriched with minerals and vitamins. Significant micronutrient deficiency is therefore less likely at this age than later when diet is based on unfortified cows' milk. Although the deficiency of another nutrient might theoretically increase energy expenditure through the inefficient use of dietary energy, the excellent growth response to energy supplements alone in young infants with congenital heart disease ${ }^{2123}$ suggests that additional nutrient deficiency is not of major importance.

Although there are no data from infants undergoing cardiothoracic surgery, postoperative morbidity has been reduced by improving the nutritional status before cardiac surgery in adults $^{25}$ and in children undergoing a variety of other surgical procedures. As these nutritional requirements may be anticipated we suggest that energy supplementation in conjunction with nasogastric feeding is instituted at the time of diagnosis to prevent growth failure, particularly when immediate surgery is not possible.

We thank the physicians and surgeons of the cardiothoracic unit, Hospital for Sick Children, Great Ormond Street for permission to study their patients and Kabi Pharmacia, Stockholm, mission to study their patients and Kabi Pharmacia, Stockholm,
Sweden for their support of this study. JSB and PCH are generously supported by Children Nationwide and Kabi Pharmacia.

1 Mehrizi A, Drash A. Growth disturbance in congenital heart disease. F Pediatr 1962; 61: 418-29.

2 Menon G, Poskitt EME. Why does congenital heart disease cause failure to thrive? Arch Dis Child 1985; 60: 1134-9.

3 Schulze K, Stefanski M, Masterson J, et al. An analysis of the variability in estimates of bioenergetic variables in the variability in estimates of bioenergetic
preterm infants. Pediatr Res 1986; 20: 422-7.

4 Davies PSW, Ewing G, Lucas A. Energy expenditure in early infancy. $\mathrm{Br} \mathcal{F}$ Nutr 1989; 62: 621-9.

5 Jones PJH, Winthrop AL, Schoeller DA, et al. Validation of doubly labelled water for assessing energy expenditure in infants. Pediatr Res 1987; 21: 242-6.

6 Roberts SB, Lucas A. Measurements of urinary constituents and output using disposable napkins. Arch Dis Child 1985; 60: 1021-4.

7 Gregory JW, Greene SA, Jung RT, Scrimgeour CM, Rennie MJ. Changes in body composition and energy expenditure after six weeks' growth hormone treatment. Arch Dis Child 1991; 66: 598-602.

8 Weir JBdeV. New methods for calculating metabolic rate with special reference to protein metabolism. I Physiol 1949; 109: 1-9.

9 Black AE, Prentice AM, Coward WA. Use of food quotients to predict respiratory quotients for the doubly-labelled water method of measuring energy expenditure. Human Nutrition: Clinical Nutrition 1986; 40C: 381-91.

10 Cole TJ. A method for assessing age-standardised weightfor-height in children seen cross-sectionally. Ann Hum Biol 1979; 3: 249-68.

11 Schoeller DA, van Santen E, Peterson DW, Dietz W, Jaspan J, Klein PD. Total body water measurements in humans with ${ }^{18}$ Oand ${ }^{2} \mathrm{H}$ labelled water. Am $\mathcal{F}$ Clin Nutr 1980; 33: 2686-93.

12 Fomon SJ, Haschke F, Ziegler EE, Nelson SE. Body composition of reference children from birth to age 10 years. Am f Clin Nutr 1982; 35: 1169-75.

13 Guo S, Roche AF, Fomon SJ, et al. Reference data on gains in weight and length during the first two years of life. f Pediatr 1991; 119: 355-62.

14 Tanner JM, Whitehouse RH, Takaishi M. Standards from birth to maturity for height, weight, height velocity, and weight velocity: British children, 1965. Part II. Arch Dis Child 1966; 41: 613-35.

15 Davies PSW, Cole TJ, Lucas A. Adjusting energy expenditure for body weight in early infancy. Eur $\mathcal{F}$ Clin Nutr 1989; 43: 641-5.

16 Department of Health. Report on health and social subjects 41 . Dietary reference values for food energy and nutrients for the United Kingdom. London: HMSO, 1991.

17 Kennaird DL. Oxygen consumption and evaporative water loss in infants with congenital heart disease. Arch Dis Child 1976; 51: 34-41.

18 Stocker FP, Wilkoff W, Miettinen OS, Nadas AS. Oxygen consumption in patients with heart disease. $\mathcal{f}$ Pediat 1972; 80: 43-51.

19 Pittman JG, Cohen P. The pathogenesis of cardiac cachexia. N Engl f Med 1964; 271: 403-9.

20 Spady DW, Payne PR, Picou D, Waterlow JC. Energy balance during recovery from malnutrition. Am $\mathcal{f}$ Clin Nutr 1976; 29: 1073-88.

21 Jackson M, Poskitt EME. The effects of high energy feeding on energy balance and growth in infants with congenital heart disease and failure to thrive. Br $f$ Nutr 1991; 65: 131-43.

22 Payne PR, Waterlow JC. Relative energy requirements for maintenance, growth, and physical activity. Lancet 1971 ; ii: $210-1$.

23 Schwarz SM, Gewitz MH, See CC, et al. Enteral nutrition in infants with congenital heart disease and growth failure. Pediatrics 1990; 86: 368-73.

24 Ronholt Hansen S, Dorup I. Energy and nutrient intakes in congenital heart disease. Acta Paediatr 1993; 82: 166-72.

25 Blackburn GL, Gibbons GW, Bothe A, Benotti PN, Harken DE, McEnany TM. Nutritional support in cardiac cachexia. $\mathcal{F}$ Thorac Cardiovasc Surg 1977; 73: 489-95. 